since neither is suitable to maintain well-rounded development when given exclusively.

Not only is weaning often undertaken on mistaken and insufficient grounds, but the argument is frequently advanced that where success in breast-feeding appears to be doubtful, better results are obtained by beginning total artificial feeding soon after birth. This argument can obtain only -when the artificial feeding of the infant is in the most expert hands, and the infant can remain under close supervision for a long period. With the vast majority of infants such supervision, for many reasons, is not possible. The pitfalls of unsupervised bottle-feeding are many and the danger of subnutrition or overfeeding great. The safer progress of the infant receiving breast-milk needs no argument. Breast-feeding, at least in competent part, can be established in many cases which at first seem rather unpromising, and any method which enables us to promote the normal growth of the infant by utilizing the physiological nutriment from the mothers' breasts while we are endeavoring to establish its permanency, is worth trying.

Since it will undoubtedly be admitted that to inaugurate a gain in weight in the newly-born infant is a long step toward its ultimate welfare and subsequent expectation of life, these measures are submitted for your consideration at this time.

807 Madison Avenue.

\section{FEEDING OF FATS TO INFANTS AND THE DIFFICULTIES ENCOUNTERED *}

CHARLES DOUGLAS, M.D.

Professor of Children's Diseases in the Detroit College of Medicine DETROIT

A great deal has been written during the last three years regarding the propriety of feeding fats to infants during the first year. When the percentage method of feeding was introduced all the teaching was on a plan of imitating very largely the percentages of fat protein and sugar in human milk. Many elaborate formulas were made and appeared in pediatric text-books showing how low and high percentages of each of these ingredients could be combined in a milk formula. In the more recent text-books fewer of these formulas appear. All physicians who are paying close attention to feeding young infants during the first year soon come to realize that the percentages of each food must be adjusted to the infant's digestive power rather than that the infant should be adjusted to some formula which may be thought suitable for an infant's dietary.

Experienced pediatrists realized that the first idea of imitating. with cow's milk the proportions of fat protein and sugar in human milk would rarely give success. Consequently they found it necessary to give to each infant only that amount of each ingredient which the results, as shown by the infant's comfort and growth, were found to be suitable. Having once seen this necessity it soon became apparent that the amount of fat which could be fed to infants varied very much with their digestive power, their age and previous disturbances of the intestinal mucosa.

About three years ago occasional articles appeared in the pediatric journals reporting instances in which an infant could digest no fat and its dietary consequently

* Rear in the Section on Diseases of Children of the American Medical Association, at the Sixty-First Annual Session, held at St. Jouis, June, 1910. was constructed entirely of protein and carbohydrates. These articles continue to appear occasionally. It is not my object to report more of these cases, but rather to consider the digestion of fat in its various proportions and the bad effects resulting from imperfect digestion of fats and the foods containing them. Consequently these foods must be limited or avoided entirely.

Some ten years ago, when trying to follow the teachings on percentage feeding, I encountered great. difficulties in feeding infants with the 4 per cent. proportion advocated so much at that time, it being the proportion in human milk. Nearly all physicians had the same experience, yet some continue it still. A great wave of high percentage fat feeding was spread through the country by physicians generally, who read this teaching, but had little opportunity to practice it. The result was that all pediatrists found the parents soon thoroughly imbued with the necessity of feeding cream liberally to their infants on the ground that, as they thought, it was the best part of the milk, and they were also taught that the free use of it would overcome the constipated condition of the bowels so much to be contended with in hand-fed infants. This practice still continues among the laity, and a large part of the medical profession also, and is the source of a great deal of harm to the little ones, and in only rare cases is it beneficial from a cathartic point of view. On the contrary, in most infants it causes a very obstinate constipation.

Newly born infants generally digest fat more perfectly during the first few weeks of their lives than they do in later months. Very rarely will an infant digest perfectly more fat after the second month than it has done prior to that time. In my experience there are very few of them who will at any time digest more than 2 per cent. As I do no obstetrical work, I have only a very limited number of infants to feed continuously from birth. Most of my patients are infants who have been imperfectly nursed or improperly fed for several weeks before I see them. I find that these infants have almost invariably been fed with a too high percentage of. fat and that either they were born with imperfect fat digesting power or very rapidly acquired it through overfeeding of it. My experience shows that over-feeding either fat, protein or sugar will very soon materially limit or entirely destroy the power to digest that food. In most of these cases which come to me I have been compelled for many years to reduce the fat to less than 1 per cent. and in very many of the cases to remove it entirely as far as it can be removed from milk by the gravity process. The amount left in gravity milk after many hours' exposure to ice or cold air of winter is less than one-half of 1 per cent. Even this amount causes difficulty to some infants, and I have found that the fat-free milk obtained by the separator process was preferable in some families to that obtained by the gravity process. This appears to me to be due to a lesser amount of fat in the separated milk and the better condition of the sugar in the newer milk from the separative process. I always find less difficulty in feeding fat to normal infants during the first months than to those who are older.

It is a serious mistake to increase the proportion of fat in food for its laxative effect. If a small increase of one-half of 1 per cent. does not promptly produce some softening effect on the stools no further increase should be made, as usually it decomposes in the bowel and poisons the child or forms crumbly, dry, soapy stools, which increase the constipation. It is very desirable that 
each infant should receive the highest percentage of fat which it can digest properly. It is equally important that the fat should not be increased when there is the slightest evidence of its imperfect digestion. There is no food the digestion of which is so quickly destroyed as fat. There is also no food which will so completely check the growth and development of an infant when it is imperfectly digested. It requires less than one-half of 1 per cent. of imperfectly digested fat in an infant's dietary to prevent it from growing, to disturb its sleep, to destroy its color and to pave the way for marasmus and other forms of malnutrition.

The early and prompt recognition of fat indigestion is absolutely necessary for successful infant feeding. The physician must have clear ideas on this subject and have the strength of his convictions in order to overcome the strong desire of all mothers and nurses to feed cream too freely to their infants. Imperfect digestion of fat is shown by the variable and lessened appetite of the infant, by the gassy condition of the stomach and bowels, by the disturbed sleep, by the pale-yellow color of the skin, by the tendency to vomit from one-half to one hour after feeding, by the offensive odor of the stools, by their pale, greasy, rancid-butter, or dry, crumbly appearance, and by the failure of the infant to grow. Any one of these symptoms is enough evidence to the experienced pediatrist that the proportion of fat in the food is too high and that success demands its reduction or entire removal. In the young infant during the first few months this difficulty of fat feeding applies to the milk fat only. As infants become older and able to take other foods the proportions of fat which these other foods contain will usually govern their suitability in preparing the infantile dietary. In the nitrogenous line experience shows that the poor milk fat digestor cannot take the yolk of egg or the fat of oatmeal.

Where an infant's milk digestive power has been reduced through over-feeding of milk it often becomes necessary to substitute egg-albumen for this deficiency. Care must always be taken to commence with the albumen only and avoid the yolk, as the latter contains the fatty part of the egg. In feeding broths to such infants care must always be taken to remove all fat by cooling it before feeding, or, better still, to feed beef juice made by the cold-water process. 'The same difficulty applies to the use of cod-liver oil in most cases.

In selecting a suitable carbohydrate for these infants with defective fat digestive power, experience shows that oatmeal can rarely be fed, as it contains over 6 per cent. of fat. My experience is that the fat of oatmeal acts similarly on the child's digestive organs to the fat of milk. There is scarcely an infant who has lost the power to digest milk fat who can take any proportion of oatmeal.

Barley contains over 2 per cent. of fat. These infants do not show the same difficulty in digesting barley fat that they do with the oatmeal fat, but there is a large number of them who are unable to appropriate the fat of barley, and consequently fail when fed barley flour as a part of their dietary. These facts are very much to be regretted, as these two carbohydrates are very valuable and give excellent results in those infants who can digest them perfectly.

My experience is that these infants with feeble fat digesting power succeed better when fed rice starch than they do with any other. Rice contains less than onehalf of 1 per cent. of fat, a low percentage of protein but a high and easily digested proportion of starch.
After several years' experience in using the different forms of starches I find very few of these infants with weak or damaged digestive glands who cannot metabolize a proper proportion of rice in their daily dietary.

When an infant cannot appropriate fat it is compelled to exist and grow on two fonds only-proteins and carbohydrates-when Nature designed three as necrssary for growth and development. 'The result is that these infants always make slow progress during the first six to eight months of life. As their dietary must be made up of proteins and carbohydrates it is important to select those containing the least fat.

The most suitable proteins are found in nitrogenous foods, skimmed milk, white of egg and meat juice. In these the fat is separated with little difficulty; but when we look for a carbohydrate free from fat we instantly meet with difficulty; as Nature has so mingled fat with the protein and carbohydrate in all cereals that it is impossible of such separation as can be accomplished in the nitrogenous foods. The best we can do is to select that cereal which contains the least fat with no other objectionable food feature.

A look at the chemical composition of the cereals suitable for infant foods shows the following, according to the latest reliable analyses of Wiley, Bryant, Atwater and others:

\begin{tabular}{|c|c|c|c|c|}
\hline 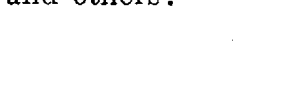 & $\begin{array}{l}\text { Proteins, } \\
\text { per cent. }\end{array}$ & $\begin{array}{c}\text { Fat, } \\
\text { per cent. }\end{array}$ & $\begin{array}{l}\text { Carbo- } \\
\text { hydrates, } \\
\text { per cent. }\end{array}$ & $\begin{array}{l}\text { Crude } \\
\text { fiber, } \\
\text { per cent. }\end{array}$ \\
\hline Wheat flour .. & 14. & 1.90 & 71.20 & \\
\hline Rye ...... & 12.25 & 1.50 & 71.75 & 2.10 \\
\hline Barley .... & 11.00 & 2.25 & 69.55 & 3.85 \\
\hline Oats $\ldots \ldots \ldots \ldots$ & 11.73 & 6.04 & 55.43 & 10.83 \\
\hline$\ldots \ldots \ldots \ldots \ldots$ & 10.00 & 4.25 & 71.75 & 1.75 \\
\hline Rice & 7.50 & 0.40 & 78.80 & 0.40 \\
\hline
\end{tabular}

These figures show that rice contains the least fat and largest amount of starch of all cereals. It also shows the smallest percentage of crude fiber. As delicate infants usually show a tendency to loose, soft stools, which are inimical to growth, this latter feature is important, as crude fiber increases the activity of the intestine and consequent watery stools. Experience shows that rice starch is the most easily digested of all starches and equally nutritious with the best of them.

989 Jefferson Avenue.

\section{ABSTRACT OF DISCUSSION}

ON PAPERS OF DRS. COTTON, DOUGLAS AND SOUTHWORTH

DR. JoHN ZAHORSKY, St. Louis: For many reasons the mother's milk is deemed inadequate and the mother is advised to give the infant one or two bottle feedings a day. Of course, it is convenient for the mother, but I think this giving of one or two bottles a day is the chief cause for producing a lack of breast-feeding. It gives a long interval in which the ducts of the breast become distended, resulting in a lessening of the activity. For several years $I$ have insisted on having the mother nurse the baby every time, and if the mother's milk is deficient I order a complemental feeding after nursing. This conserves the normal maternal nursing better than supplemental feeding. If a breast is deficient in activity, we must keep up the stimulus to that breast.

We have been taught to give the new-born infant low proteid and comparatively high fat, and this method is frequently a success; but recently we have been trying to get the nutritive ratio much higher and the difficulty we en. counter is due to the fact that an excess of casein will lead to soap stools, in that it diminishes the digestion of fat. Now, shall we try to give the young baby a low protein and 
comparatively high fat percentage, or a high protein and a comparatively low percentage of fat? European authorities deny that there is such a thing as a casein stool. I am convineed that American investigators are correct, that rarely there is "curd" in the stool which has casein as a central nucleus. The most common coagula in stools are those of soaps or fatty acids.

Dr. EfFa V. Davis, Chicago: I agree with the practical point brought out by Dr. Southworth; I have used this method several years. In the last few years I have discovered that it is in the afternoon and evening that the mother gives the least milk; frequently in the morning she will give a sufficient quantity. In such cases I compromise witl the patient and ask her to give complemental feeding in the afternoon. That can be determined, if there is any doubt about it, by weighing the baby before and after nursing.

I want to compliment Dr. Cotton on some of the points brought out in his paper. It seems to me that civilization is hardly civilization if it deteriorates the race. Environment has much to do with development, and I hardly eare to take the time to go into a discussion of monogamy, but there is a necessity for pointing out these facts in their influence on breast feeding. It is an easy matter to tell patients what to do, but the difficulty is to have these things done, for there are two members in the family, the husband and the wife. If Dr. Cotton is right then we must take into consideration the sexual relations in the result to the nursing infant, and what sexual relations have to do with the degeneration of the child. I try to convince my families that these things must be taken account of and that they should not be heedless in reproduction without realizing what it means. One Chicago physician illustrated the point that frequent repraduction does not necessarily imply higher intelligence or physical ability, by citing the conditions that exist among tame and wild ducks. The keen, clever, courageous wild duck reproduces its kind once in a season, but the tame duck, which procreates the year round, is a stupid, lumbering creature that can hardly fly over the garden wall.

DR. J. P. SEDGwick, Minneapolis: I think that those of us who have tried complemental feeding have found it of great value. I think we can well use even more accurate methods, in difficult cases, $i$. $e$., weigh the children before and after nursing and then supplement the breast milk with enough food to come somewhere near the caloric requirement. I do think that is a valuable check, although we cannot feed the child exactly according to its caloric need. The French have recently done much along this line and they state that if we want to keep up breast feeding we must keep up the evacuation of the breasts by the complemental method. If we wish to stop the flow of milk we should give supplemental feedings.

Dr. John Lovert Morse, Boston: I want to come to the rescue of supplemental feeding. There is no doubt that all Dr. Zahorsky has said is perfectly true, but there is another side to the question. I have found that the modern woman, with all her social and family duties, has to have more than two or two and a half hours at one time away from home, and I have found that she does better and can nurse her baby longer with a supplemental feeding than if she tries to nurse it every time.

In considering the disturbance of the digestion of fat in babies we must take into consideration whether we are dealing with a well baby or with a sick baby. The conditions are entirely different. We have heard a great deal from the Germans about the dangers of fat. In the last article I saw in a German magazine it was claimed, however, that the primary cause of disturbance was the carbohydrates and that the disturbance of digestion of fat was secondary.

DR. C. F. WAHRER, Fort Madison, Ia.: While I agree with Dr. Zahorsky, I want to sound a note of warning. It is so much easier to put some food in a bottle and turn it over to some member of the family to feed the baby while the woman is thus allowed to go about her various duties, that there is great temptation 10 use this method of feeding. In case the child dies, we are taught that administration of 20 grains of citrate of potash 3 times daily will aid in drying up the milk. Now careful observers at Johns Hopkiris advise doing nothing at all, but let it dry up, and careful experiments' have shown that if let alone thus the breasts dry up sooner. There is danger in supplemental feeding. Let us teach the mother to give the child all she can give and then, if necessary, give it complemental feeding. We have lazy mothers, incompetent mothers, and mothers who are bound up in their social duties, who are only too glad to turn the child over to the supplemental bottle. In rural districts many people bring up their babies on cows' milk and add half as much again of cream and the children do well. It is wonderful on what things some children will thrive and grow fat.

Dr. Jules M. Brady, St. Louis: Since the publication of Czerny and Keller's paper, I have made observations along this line and the clinical results prove conclusively that babies fed low fat percentage, particularly during the first two months, do far better than those fed on a comparatively high percentage of fat. The use of top milk in making dilutions has not been so successful in my hands as the use of skim milk, with its 0.5 per cent. of fat. As to the curds in infants stools the fat alone and proteid alone seem not responsible, both must be present. When fat-free acidified milk is given curds never occur, as the proteid being in the form of the lactate is not coagulable.

Dr. C. G. KerLEY, New York: In almost every discussion on nursing and infant-feeding, the supposed indifference of the young mother, the so-called educated young mother, or the young mother in good society, whatever this may mean, is strenuously berated. By those who know little or nothing of New York City, all sorts of vice and corruption are supposed to abide in that city, but my observations of the mothers of New York City are very extensive, and I have found that the young mother who has had the best opportunities in life, makes the best mother, and when this young woman does not appreciate her duties in the matter of nursing and supervision of her children, it is usually the fault of her physicians and other advisers. Such a young woman has been educated sufficiently to appreciate scientific principles, and when it is explained to her that a baby's stomach is intended to digest mothers' milk and not cows' milk, and how the organ is adapted to human milk, or how human milk is made to fit the organ, no one will appreciate it more quickly and act on it more satisfactorily than the educated young mother; but the physician must be sufficiently well informed to explain this. Then this so-called high-strung mother will nurse her baby, or if she is unable to do it, she will see to its every want and fulfill her function in every respect to the best of her ability. It is difficult for me to understand why a young woman, with all the finer instincts of culture and education, should, on the advent of a child, be transformed into a creature who neglects her offspring, ranking her lower than the lower animals. In a very active work for twenty-two years among every possible class of mother, I cannot understand why $I$ have not seen some of this supposed indifference and neglect.

If you wish one of these young mothers to discontinue her nursing function, then have her discontinue her former method of life. Tie her down to the baby and keep her there and very likely the nursing will be short-lived. She has been accustomed probably to an active girl's out-of-door life, as every girl should who has an opportunity. I have these mothers continue their activities, horseback riding, golf, afternoon teas, the theater, surf-bathing; in fact, one of the secrets of continuing a reasonably good milk-supply in a nursing mother, regardless of station, is to have her lead a happy and congenial life, in both a social and an occupational way. The diet practically should be the diet to which she was accustomed before she became a mother. One cannot take a high-class young mother and make a drudge and an animal out of her with success, just because she happens to have a baby. In order that she may be a successful mother, there will have to be one or two supplemental feedings a day. The statement that one bottle or two bottles a day, supplied the baby in order that the mother may be given more freedom, is a means of gradually curtailing the milk 
supply or cutting short the nursing period is absolutely without foundation. On the contrary, by this method I am able to have the mother continue nursing langer by 2 or 3 months than when she is required to nurse the child at each feeding.

DR. A. C. Cotron, Chicago: I never listened to a discussion on infant-feeding : where there was so much good sense manifest and so little foolishness. I don't know of anything that was overlooked except that perhaps there might have been a little more emphasis laid on the utilization of mother's milk, even if it be in extreme reduction. There should always be an effort made to stimulate the lacteal secretion; even though there be but two or three grams of it, it is worth saving. I think many of you will remember a paper presented by Dr. Wentworth, of Boston, on the exciters of secretion; it was very suggestive. It is fair to assume that there is something in mother's milk wlich acts as an exciter to the digestive functions that we cannot imitate in any artificial food. Even only. a gram or two of mother's milk may be sufficient to promote digestion. That was the only point that I did not think received sufficient emphasis.

As to the digestion of fats. I presume we shall never come to an agreement. Dr. Morse hit it exactly on the head when he said enough. was enough and too much was too much. No exact. rule can ever be laid down for the individual baby. The differences between the fat of cows' milk and the fat of maternal milk are sufficient to prevent any comparison as to quantity ever being attempted.

Dr. Charles Douglas, Detroit: I use complemental or supplemental feeding according to the needs of the woman. I may use the supplemental method until the woman recovers her strength and is able to do the whole work herself. The point of stimulating the breast at intervals is good, but that stimulation may be once in 2 hours, or once in 4 hours, or once in 6 hours, and if the woman is worn out or exhausted, I think she does better with 4 or 6 hours' rest. In a strong woman I think two hours is better. But the woman herself usually argues that substituting every alternate meal is better for her. I think that as a regular practice it is not good, although I continually do it with women who have to get away from the house a few hours. Putting a young woman in the house and in charge of a baby when she is not educated along that line is a great tax, and if she can get a certain amount of rest it is a great advantage.

DR. T. S. SouthworTh, New York: I employ supplementary feeding in many cases and should limit the use of complemental feedings to the first few weeks of life, while trying to get the child started on the upward road of growth and nutrition. I make the largest use of supplementary feedings later. I am glad Dr. Davis spoke of a fact that has not been mentioned in certain text-books, namely: that in the afternoon and evening the nursing mother is liable to have the least milk. Any one. who follows this out can easily recognize the fact by weighing the children in the morning. and in the afternoon and evening, both before and after nursing. It is a matter we should remember in giving nourishment to the mother in order to improve the breast milk and also with reference to the needs of the infant itself. When with deficient milk it is necessary to substitute bottle feedings in part for the breast, I am accustomed to have the mother nurse, particularly in the afternoon, each time from both breasts, thus maintaining the stimulation of the breasts. This is satisfactory in keeping up the flow of the breast milk so long as the number of bottles does not exceed the number of nursings. The mother nurses from both breasts at one nursing and gives the bottle at the next feeding. The only difficulty with Dr. Sedgwick's method, which would be excellent where one could weigh the child before and after nursing and adjust the amount accordingly, is that it would be too complicated to employ in very many cases.

Creosote in Bromchopneumonia-Creosote is indicated in all stages of the disease: It should be prescribed in small doses several times a day. The tent made of bed-sheets hung around the bed and moistened with creosote, oil of eucalyptus and the like is of service, especially in tracheobronchitis.H. B. Sheffield, in Merck's Archives.

\section{YERSIN-ROUX SERUM IN THE TREATMENT OF PLAGUE *}

\author{
A. N. SINCLAIR, M.D.
}

A. A. Surgeon U. S. Public Health and Marine-Hospital Service; Superintendent Leahi Home; Member of Territorial Board of Medical Examiners

HONOLULU, T. H.

By permission of Dr. Ramus, chief quarantine officer of the Territory of Hawaii, I submit for consideration the following report on the treatment of three cases of plague, by Yersin-Roux serum.

The action of Yersin-Roux serum in the treatment of this disease has been so greatly a matter of dispute among those who have used it that this report is given in the hope of causing at least a revision of opinion among those who condemn it as useless.

My first experience in the treatment of plague by means of this serum, in $190 \%$, caused me to regard its use most favorably. Unfortunatèly, the records of those cases, about 20 in number, were thought by me to be in the possession of the Territorial Board of Health, but cannot now be found. But the three cases I am about to report show admirably the chief points observed at that time, and I am enabled to use them as types illustrative of the action of the serum in cases of plague.

The three patients were Russian immigrants, all of the same family: the father aged 45 , one daughter aged 15 , and another daughter aged 8 .

For the purpose of classification I have designated the older daughter as Case 1 , the father as Case $z$ and the younger daughter as Case 3.

Case 1.-Russian girl, aged 15.

History.-I first saw this patient at the Immigration Station on June 7,1910 , at about 11 a. $m$. She had complained of headache and nausea the day before, with some fever, and her illness was attributed to the eating of preserved eggs, which her father had brought with him from Siberia. When I saw her, at the request and in consultation with Dr. Ramus, she was in bed, feeling too ill to be about. The facies at once impressed me as suggestive of plague: the wrinkled brow, half-closed eyes, and drooping mouth united in producing that "worried look" so frequently accompanying plague.

Examination.-A swelling was made out in the neck, under the angle of the jaw. The tumor was about the size and shape of a hen's egg-indurated, but uniformly smooth to the touch, and showing no evidence of its multiglandular structure. It was exceedingly painful on manipulation, although there was but little redness or edema of the skin. I have repeatedly noticed that the skin over a cervical bubo is not nearly so frequently affected with redness and edema as the skin over plague buboes in other situations. Temperature was $102 \mathrm{~F}$., and in view of the fact that the girl's father was in a similar condition (but with a bubo in the right groin, in which a bacillus resembling that of plague had been found), a provisional diagnosis of plague was made. The gland was not punctured or incised for examination, however, as owing to the difficulty in securing healing, or even preventing sloughing, in buboes' so treated, I have long since avoided tampering with a bubo in the cervical region, where the occurrence of sloughing can so easily endanger so many important structures.

Treatinent.-The patient was removed to Quarantine Island, and on June 8 I was detailed by Dr. Ramus to take charge of her and the other patients. On this date her condition was much more serious, the hebetude having increased, and there being considerable pain in the chest on the left side. The percussion note over the whole of the front of the chest as far down as the cardiac dulness was diminished in reson1910 .

* Read before the Hawailan Territorial Medical Society, July, 